\title{
Oncocitoma renal gigante
}

\author{
M. Álvarez Ardura, V. Hernández Cañas, J.M. de la Morena Gallego, \\ D. Rengifo Abbad, F. González-Chamorro Ladrón de Guevara, C. Llorente Abarca \\ Servicio de Urología. Fundación Hospital de Alcorcón. Madrid.
}

Actas Urol Esp 2005, 29 (8): 791-793

\section{RESUMEN \\ ONCOCITOMA RENAL GIGANTE}

El oncocitoma renal es un tumor benigno derivado de las células del túbulo renal distal. Aunque no es muy frecuente, representa entre el 3-7 \% de las masas renales. La mayoría de las ocasiones se presenta como un hallazgo incidental en pruebas de imagen realizadas por otros motivos. El diagnóstico diferencial preoperatorio con el carcinoma de células renales es complejo y a menudo sólo se puede confirmar después de la cirugía. Presentamos un caso clínico de oncocitoma renal de gran tamaño diagnosticado mediante una ecografia abdominal realizada por molestias en hipogastrio. Revisamos el enfoque diagnóstico y terapéutico de este tipo de tumores.

Palabras clave: Oncocitoma renal, carcinoma de células renales.

\section{ABSTRACT \\ GIANT RENAL ONCOCYTOMA}

Renal oncocytoma is a benign neoplasms arising from cells of the distal renal tubule. They acount for 3-7\% of all renal tumors. most are incidental findings. Differential diagnosis with renal cells carcinoma is often difficult. Here we report a case of big renal oncocytoma as an incidental finding while performing an abdominal ultrasound in a patient with low abdominal pain. We also review the diagnostic an therapeutic approach in this kind of malignancies.

Keywords: Renal oncocytoma, renal cells carcinoma.

$\mathrm{E}$ oncocitoma renal es un tumor benigno derivado de las células del túbulo renal distal ${ }^{1}$. Es una neoplasia poco frecuente, aunque no rara, que representa aproximadamente el 3,2-7\% de las masas renales primarias ${ }^{2}$.

La mayoría de los pacientes (56-91\%) son diagnosticados de forma incidental ${ }^{3}$. Los síntomas mas frecuentes en los pacientes que los presentan son dolor en flanco (4\%), masa abdominal (4\%) y hematuria $(3 \%)^{4}$.

En la mayor parte de los casos, el tumor se presenta de manera unilateral. Los tumores bilaterales o multifocales representan menos del 5\% de los $\operatorname{casos}^{5}$.

La distinción entre el oncocitoma y el carcinoma de células renales (CCR) es importante porque puede permitir abordajes terapéuticos menos agresivos ${ }^{3}$. La clínica, los hallazgos radiológi- cos, la histología y el análisis genético e inmunohistoquímico pueden orientar el diagnóstico, pero no son patognomónicos, siendo en ocasiones difícil realizar un diagnostico diferencial, en especial si el CCR es de la variedad cromófoba, un subtipo de características histológicas similares a las del oncocitoma.

\section{CASO CLINICO}

Paciente de 83 años con antecedentes personales de hipotiroidismo y degeneración macular que es remitida a nuestro servicio tras evidenciarse en un estudio ecográfico, realizado por molestias abdominales inespecíficas, una masa renal derecha de gran tamaño (Fig. 1). En el momento de acudir a consultas la paciente se encontraba completamente asintomática. 


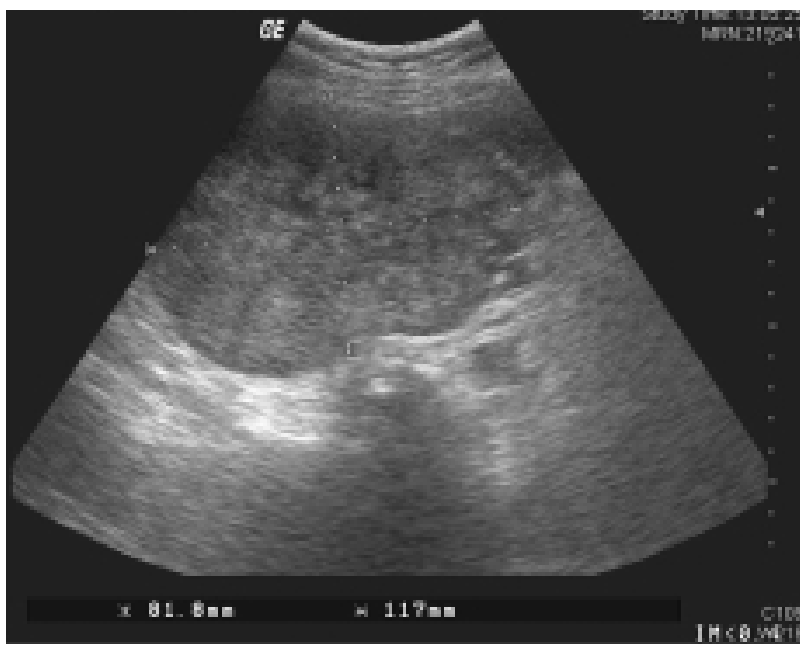

FIGURA 1. Imagen ecográfica en la que se observa una masa sólida de $15 \times 8 \times 12 \mathrm{~cm}$ en hipocondrio-fosa renal derecha, dependiente del riñón derecho y que comprime vesicula biliar. No se observan LOES hepáticas.

En la exploración física, encontramos una paciente con buen estado general, siendo el único hallazgo significativo una masa en flanco derecho, de consistencia dura y no adherida a planos profundos. No se palpan adenopatías regionales.

En el TAC abdominopélvico se confirman los hallazgos de la ecografía previa, observándose una masa renal de $13 \times 12 \times 11 \mathrm{~cm}$., que capta contraste y con centro necrótico. En el estudio no se evidencian adenopatías regionales. Como hallazgos secundarios se encontraron múltiples vasos perirrenales y quistes de Tarlov en el canal raquídeo. El juicio diagnóstico radiológico es de masa renal compatible con hipernefroma (Fig. 2 y 3)

Con el diagnóstico de masa renal sólida derecha, compatible con neoplasia renal, se decide tratamiento quirúrgico mediante nefrectomía radical derecha.

Los hallazgos intraoperatorios fueron una masa renal derecha de gran tamaño dependiente de polo inferior, que desplazaba cranealmente el riñón y comprimía los grandes vasos. No se encontraron adenopatías.

Histológicamente, a nivel macroscópico, se objetiva una tumoración sólida, bien circunscrita, que destruye gran parte del riñón y con unos $13 \mathrm{~cm}$. de diámetro máximo. Al corte, es un tumor anaranjado que presenta una cicatriz estrellada central. Presenta un crecimiento expansivo pero no infiltra cápsula renal, sistema pielo-calicial ni vasos renales. El escaso

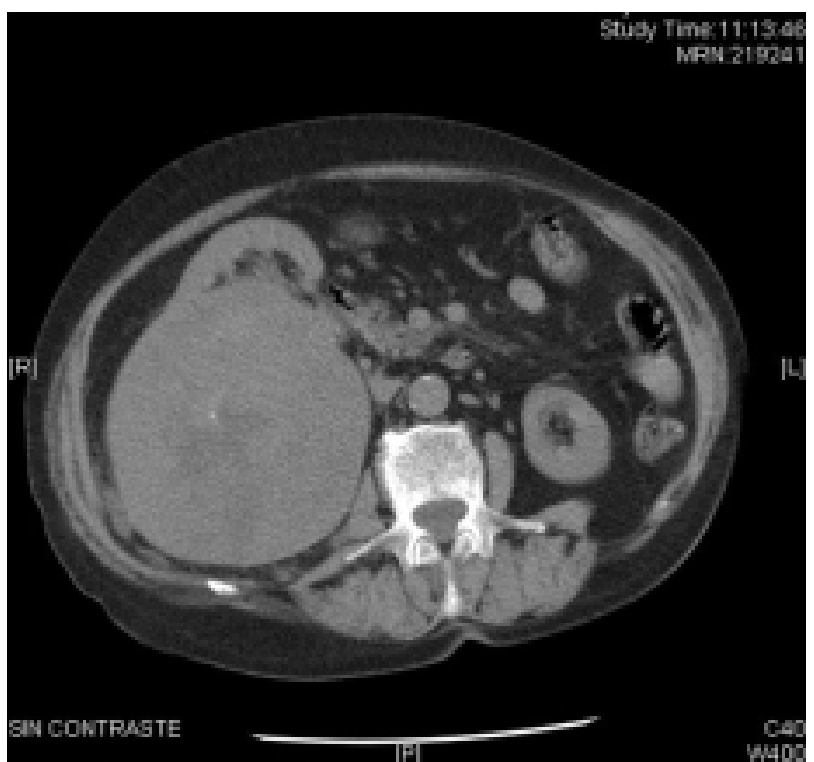

FIGURA 2. TAC abdominopélvico sin contraste.

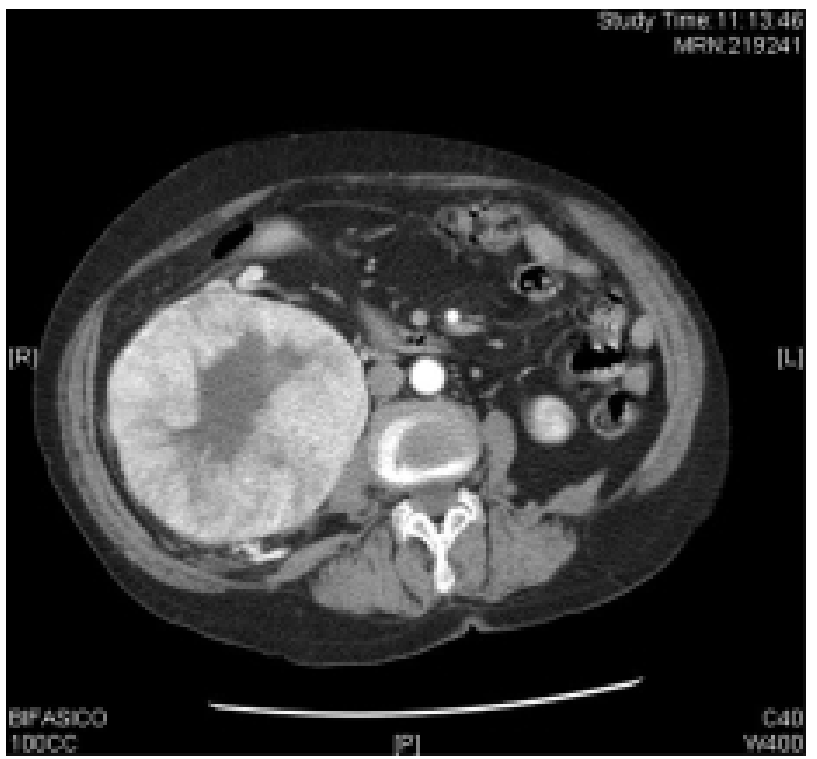

FIGURA 3. TAC con contraste en el que se observa gran masa renal derecha, con centro necrótico.

parénquima residual, situado en polo inferior, no muestra alteraciones.

Desde el punto de vista microscópico, el tumor se encuentra constituido por células redondeadas o poligonales de citoplasma densamente eosinófilo, núcleo redondeado con cromatina dispersa y nucleolo central, que se disponen formando nidos compactos, acinos o túmulos. Se aprecia invasión de la cápsula renal sin sobrepasarla, estando los vasos respetados. El diagnóstico anatomopatológico es de oncocitoma renal. 


\section{DISCUSION}

El diagnóstico diferencial preoperatorio entre oncocitoma renal y CCR es impreciso ya que no hay signos clínicos patognomónicos que los diferencien ${ }^{1}$.

Radiológicamente, el OR se presenta en el TAC como una masa esférica homogénea que a veces presenta una cicatriz central. $\mathrm{El}$ aporte arterial sigue un patrón en "rueda de carro". Por el momento, las técnicas de imagen que disponemos no nos permiten distinguir en todos los casos entre el OR y una lesión maligna ${ }^{2}$. La tomografía por emisión de positrones (PET) puede ser una opción a considerar en el futuro, pero su papel todavía ha sido poco estudiado ${ }^{3}$.

En cuanto al uso de la punción aspiración de aguja fina (PAAF) o de la biopsia percutánea, éste todavía es controvertido. El diagnóstico diferencial entre OR y CCR (sobre todo la variedad cromófoba) es complejo por el solapamiento de las características histológicas y porque pueden presentarse simultáneamente hasta en un $10 \%$ de los $\operatorname{casos}^{5}$. Así, algunos autores consideran que estas pruebas juegan un papel muy limitado ${ }^{6}$, mientras que otros afirman que la combinación del estudio con microscopio óptico, inmunohistoquímica (vimentina, citoqueratina, hierro coloidal de Halle) y microscopio electrónico es útil para el diagnóstico diferencial preoperatorio ${ }^{7}$. El hallazgo de tumores múltiples (6\%), bilateral (5\%) o el desarrollo de tumores metacrónicos (4\%) también dificulta el diagnóstico y condiciona el tratamiento ${ }^{5}$.

$\mathrm{El}$ abordaje terapéutico quirúrgico comprende un abanico de opciones como la nefrectomía radical, nefrectomía parcial y procedimientos ablativos tisulares (radiofrecuencia, crioablación, etc.) ${ }^{2}$ El tratamiento standard es la extirpación quirúrgica, pero todavía no hay acuerdo sobre la extensión de la misma. Para algunos autores, los mejores resultados se alcanzan con la cirugía radical ${ }^{3}$, puesto que no podemos estar seguros del diagnóstico preoperatorio. Los procedimientos conservadores quedarian reservados para pacientes muy ancianos, con patologías médicas graves asociadas, compromiso de la función renal o enfermedad bilateral ${ }^{2}$.

La realización cada vez mas frecuente de la ecografía para el estudio de diferentes patologías permite el diagnostico de lesiones renales mas pequeñas o incidentalomas (diámetro medio de $3.2 \mathrm{~cm}$.) que junto con la mejora del diagnóstico preoperatorio permite el planteamiento de una cirugía conservadora, siempre que sea técnicamente posible ${ }^{8}$. No hay que olvidar el comportamiento benigno de estos tumores y que la invasión microscópica linfovascular o de la grasa perirrenal no modifica el buen pronóstico de los mismos.

\section{REFERENCIAS}

1. Banks, K.W., Cherullo, E.E., Novick, A.C: Giant renal oncocytoma. Urology 2001; 57(2):365-366,

2. Romis, L., Cindolo, L., Patard, J.J., Messina, G., Altieri, V., Salomon, L. et al: Frequency, clinical presentation and evolution of renal oncocytomas: multicentric experience from a European database. European Urology 2004; 45:53-57,

3. Chao, D.H., Zisman, A., Pantuck, A.J., Freedland, J.W., Said J.W., Belldegrun, A.S: Changing concepts in the mamagement of renal oncocytoma. Urology 2002; 59(5):635-642.

4. Pérez-Ordoñez, B., Hamed, G., Campbell, S., Erlandson, R.A., Russo, P., Gaudin, P.B., Reuter, V. E: Renal oncocytoma: A clinicopathologic study of 70 cases. The American Journal of Surgical Pathology 1997; 21 (8):871-883.

5. Dechet, C.B., Bostwick, D.G., Blute, M.L., Bryant, S.C., Zincke, H: Renal oncocytoma: Multifocality, bilateralism, metachronous tumor development and coexistent renal cell carcinoma. The Journal of Urology 1999;162:40-42.

6. Schatz, S.M., Lieber, M.M: Update on oncocytoma. Current Urology 2003;4:(1):30-35.

7. Liu, J., Fanning, C.V: Can renal oncocytomas be distinguised from renal cell carcinoma on fine-needle aspiration specimens? A study of conventional smears in conjunction with ancillary studies. Cancer Citopathology 2001;93 (6): 390-397.

8. Ponholzer, A., Reiter, W.J., Maier, U: Organ sparing surgery for giant bilateral renal oncocytoma. The Journal of Urology 2002;168: 2531-2532.

Dr. M. Álvarez Ardura

Los Nardos, 145, $3^{\circ} \mathrm{B}$

28925 Alcorcón (Madrid)

E-mail: malvareza@fhalcorcon.es

(Trabajo recibido el 18 de enero 2005) 